\title{
Concentrations of besifloxacin, gatifloxacin, and moxifloxacin in human conjunctiva after topical ocular administration
}

This article was published in the following Dove Press journal:

Clinical Ophthalmology

II April 2010

Number of times this article has been viewed

\author{
Gail Torkildsen' \\ Joel W Proksch ${ }^{2}$ \\ Aron Shapiro ${ }^{3}$ \\ Stephanie K Lynch ${ }^{3}$ \\ Timothy L Comstock ${ }^{2}$ \\ 'Andover Eye Associates, Andover, \\ Massachusetts, USA; ${ }^{2}$ Bausch and \\ Lomb, Inc., Rochester, New York, \\ USA; ${ }^{3}$ Ora, Inc., Andover, \\ Massachusetts, USA
}

Correspondence: Aron Shapiro Ora, Inc., 300 Brickstone Square, Andover, Massachusetts, USA, 01810 $\mathrm{Tel}+$ I 978-685-8900

Fax + I 978-689-0020

Email ashapiro@oraclinical.com
Purpose: To evaluate the pharmacokinetic properties of besifloxacin, gatifloxacin, and moxifloxacin in the conjunctival tissue of healthy volunteers after topical application.

Methods: One-hundred eight (108) subjects were randomly assigned to receive one drop of besifloxacin ( $0.6 \%$ suspension), gatifloxacin $(0.3 \%$ solution), or moxifloxacin $(0.5 \%$ solution $)$ ophthalmic formulations in one eye prior to conjunctival biopsy. Conjunctival samples were taken from subjects at either 15 minutes, 30 minutes, 2 hours, 6 hours, 12 hours, or 24 hours after dosing.

Results: All three fluoroquinolones reached a peak mean concentration 15 minutes after dosing. The mean concentrations of besifloxacin, gatifloxacin, and moxifloxacin at 15 minutes were $2.30 \pm 1.42 \mu \mathrm{g} / \mathrm{g}, 4.03 \pm 3.84 \mu \mathrm{g} / \mathrm{g}$, and $10.7 \pm 5.89 \mu \mathrm{g} / \mathrm{g}$, respectively. Concentrations decreased with each subsequent time point. At 24 hours after dosing, concentrations of besifloxacin were measurable in 4 of 6 subjects, compared with 3 of 6 subjects for gatifloxacin and 2 of 6 subjects for moxifloxacin. Besifloxacin had the greatest mean residence time (4.7 hours) in the conjunctival tissue. With regard to methicillin-resistant strains of Staphylococcus aureus and Staphylococcus epidermidis, besifloxacin had the greatest area-under-the-curve (AUC) to $\mathrm{MIC}_{90}$ ratio. Nine percent $(9 \%)$ of study subjects $(\mathrm{N}=7)$ experienced a transient reduction in visual acuity.

Conclusion: All three fluoroquinolones were well tolerated and reached levels in the conjunctiva above the $\mathrm{MIC}_{90}$ s of methicillin-sensitive $S$. aureus and $S$. epidermidis for at least 2 hours.

Keywords: besifloxacin, fluoroquinolone, conjunctivitis, pharmacokinetics, minimum inhibitory concentration

\section{Introduction}

Bacterial conjunctivitis is normally an acute, self-limiting infection. Recent phase 3 clinical trials have demonstrated that the most common conjunctivitis pathogens are the Gram-positive species Staphylococcus aureus, Staphylococcus epidermidis, Streptococcus pneumonia and the Gram-negative species Haemophilus influenzae. ${ }^{1,2}$ In clinical practice, suspected cases of bacterial conjunctivitis are generally treated with broad-spectrum, topical antibiotics to increase the speed of recovery from signs and symptoms associated with the infection. Untreated cases of acute bacterial conjunctivitis may become chronic or may develop into a more serious condition such as bacterial keratitis. ${ }^{3}$ A recent meta-analysis compared antibiotic treatment versus placebo for acute conjunctivitis in five clinical trials $(\mathrm{N}=1034)$ and found that groups receiving an antibiotic experienced significantly less time to clinical resolution and microbial eradication. ${ }^{4}$ Faster resolution of infection translates to fewer days out 
of work or school and decreases the chance of spreading infection to others.

Several recent studies have implicated drug-resistant pathogens in bacterial conjunctivitis. ${ }^{5}$ Other studies have demonstrated an increasing frequency of resistant organisms observed in ocular infections. ${ }^{6}$ In light of this, there is a growing need for an ophthalmic antibiotic with improved efficacy against organisms such as methicillin-resistant $S$. aureus (MRSA). Even among methicillin-sensitive S. aureus ocular isolates, there is a resistance rate of $20 \%$ to ciprofloxacin and of $46 \%$ to azithromycin. ${ }^{6}$ Methicillin resistance has also been found among $S$. epidermidis ocular isolates. ${ }^{7}$

Currently, multiple broad-spectrum antibiotics are approved for the treatment of conjunctivitis. The drug approved most recently for the treatment of bacterial conjunctivitis is besifloxacin (Besivance ${ }^{\circledR}$; Bausch and Lomb, Inc., Rochester, New York, USA), a novel, synthetic chloro-fluoroquinolone (FQ) developed exclusively for ophthalmic use. Like other fluoroquinolones (FQs), besifloxacin targets DNA gyrase and topoisomerase IV, bacterial enzymes required for DNA replication. However, besifloxacin offers more balanced activity against these enzymes than do other FQs. ${ }^{8}$ In addition, besifloxacin has been found to have greater in vitro activity than gatifloxacin and moxifloxacin against several drug-resistant organisms, including MRSA and methicillin-resistant $S$. epidermidis (MRSE) (Table 1). ${ }^{7}$

A key factor in the clinical efficacy of an antibiotic is the concentration it is able to achieve in infected tissues. An antibiotic's concentration in tissue over time can be determined by pharmacokinetic (PK) studies. Parameters derived from PK studies include an antibiotic's peak concentration $\left(\mathrm{C}_{\max }\right)$ as well as its total area-under-the-concentration-versus-time curve during a 24-hour interval $\left(\mathrm{AUC}_{0-24 \mathrm{~h}}\right)$. For fluoroquinolone antibiotics, the relationship between tissue concentration and antimicrobial activity, or pharmacodynamics (PD), can then be quantified using the ratio of $\mathrm{C}_{\max }$ to $\mathrm{MIC}_{90}$, which represents the ratio of the peak concentration to the minimum concentration needed to inhibit $90 \%$ of isolates $\left(\mathrm{MIC}_{90}\right)$ of a particular pathogen. In addition, fluoroquinolone antimicrobial activity can be quantified using the ratio of the $\mathrm{AUC}_{0-24 \mathrm{~h}}$ to the $\mathrm{MIC}_{90}\left(\mathrm{AUC}_{0-24 \mathrm{~h}}: \mathrm{MIC}_{90}\right)$. These $\mathrm{PK} / \mathrm{PD}$ ratios $\left(\mathrm{C}_{\max }: \mathrm{MIC}_{90}\right.$ and $\left.\mathrm{AUC}_{24}: \mathrm{MIC}_{90}\right)$ have been used to predict clinical outcome and microbiological success as well as to predict a decreased potential for development of bacterial resistance for FQs. ${ }^{9,10}$ For FQs, which are concentrationdependent antibiotics, the $\mathrm{AUC}_{0-24 \mathrm{~h}}: \mathrm{MIC}_{90}$ is considered a more clinically relevant ratio. ${ }^{11-14}$

The purpose of this study was to evaluate the PK profiles of 3 FQs in the conjunctiva of healthy adults. Drug concentrations in conjunctiva were compared at collection intervals ranging from 15 minutes to 24 hours after a single dose. A conjunctival biopsy procedure was employed to collect tissue samples from study participants. This methodology was based on previous conjunctival biopsy studies that analyzed concentrations of ophthalmic antibiotics, including gatifloxacin and moxifloxacin. ${ }^{15,16}$ These studies examined the drug concentrations at time-points ranging from 20 minutes to 24 hours. To date, no studies have been conducted to determine the PK profile of besifloxacin in human conjunctiva. In a tear concentration PK study, topical administration of a single dose of besifloxacin $0.6 \%$ resulted in a maximum tear concentration in humans of $610 \pm 540 \mu \mathrm{g} / \mathrm{g}$, at 15 minutes post-instillation, with an average concentration of $1.6 \mu \mathrm{g} / \mathrm{g}$ or higher sustained for at least 24 hours. ${ }^{17}$

\section{Methods}

This single-dose, randomized, double-masked, activecontrolled study was conducted at one center in Andover,

Table I Minimum inhibitory concentrations $\left(\mathrm{MIC}_{90}\right)$ for besifloxacin, moxifloxacin, and gatifloxacin against selected Staphylococcus isolates

\begin{tabular}{lllll}
\hline & Number of isolates & $\begin{array}{l}\text { Besifloxacin } \\
\text { MIC }_{90}(\mu \mathrm{g} / \mathrm{mL})\end{array}$ & $\begin{array}{l}\text { Moxifloxacin } \\
\text { MIC }_{90}(\mu \mathrm{g} / \mathrm{mL})\end{array}$ & $\begin{array}{l}\text { Gatifloxacin } \\
\mathbf{M I C}(\mu \mathrm{g} / \mathrm{mL})\end{array}$ \\
\hline $\begin{array}{l}\text { S. } \text { aureus } \\
\text { MSSA-CS }\end{array}$ & 144 & 0.06 & 0.12 & 0.25 \\
$\begin{array}{l}\text { MRSA-CR } \\
\text { b. }\end{array}$ & 81 & 4 & 32 & 64 \\
$\begin{array}{l}\text { MSSE-CS } \\
\text { MRSE-CR }\end{array}$ & 50 & & & 0.25 \\
\hline
\end{tabular}

${ }^{\mathrm{a}} \mathrm{MIC}_{90}$ values were obtained from susceptibility testing of 144 methicillin-sensitive, ciprofloxacin-sensitive S. aureus isolates. ${ }^{7}$

${ }^{b} \mathrm{MIC}_{90}$ values were obtained from susceptibility testing of $8 \mathrm{I}$ methicillin-resistant, ciprofloxacin-resistant S. aureus isolates. ${ }^{24}$

${ }^{\prime} \mathrm{MIC}_{90}$ values were obtained from susceptibility testing of 50 methicillin-sensitive, ciprofloxacin-sensitive S. epidermidis isolates. ${ }^{7}$

${ }^{\mathrm{d}} \mathrm{MIC}_{90}$ values were obtained from susceptibility testing of 29 methicillin-resistant, ciprofloxacin-resistant S. epidermidis isolates. ${ }^{24}$

Abbreviations: MIC $_{90}$, minimum inhibitory concentration to inhibit $90 \%$ of isolates; MSSA-CS, methicillin- and ciprofloxacin-sensitive S. aureus; MRSA-CR, methicillin- and ciprofloxacin-resistant S. aureus; MSSE-CS, methicillin- and ciprofloxacin-sensitive S. epidermidis; MRSE-CR, methicillin- and ciprofloxacin-resistant S. epidermidis. 
Mass., between March and April of 2009. The study was conducted in accordance with Good Clinical Practices, the Declaration of Helsinki, and was approved by IntegReview Institutional Review Board, Inc. (Austin, Texas, USA). Prior to enrollment in the study, all subjects gave written informed consent and provided a Health Insurance Portability and Accountability Act (HIPAA) authorization form.

\section{Study criteria}

Subjects were healthy volunteers of at least 18 years of age and had no ocular abnormalities that would affect the parameters of the study. Best-corrected visual acuity (BCVA) had to be $0.60 \log$ MAR or better in each eye as measured on the Early Treatment of Diabetic Retinopathy Study (ETDRS) chart. Subjects were excluded if they had undergone ocular surgery less than 3 months prior to the start of the study. Women of childbearing potential were excluded if they were pregnant, planning a pregnancy, or breastfeeding. Urine pregnancy tests were performed at Visit 1, Visit 2 or $2 \mathrm{a}$, and at Visit 4 . Any subjects with known hypersensitivity or allergy to any of the study medications were excluded. In addition, subjects with a history of a bleeding disorder, bleeding complications, or fainting during surgical procedures were excluded.

The use of certain medications was disallowed for the duration of the study. These included aspirin (daily dose greater than $81 \mathrm{mg}$ ), other anticoagulants, and anti-infective medications. The washout period for these medications was 2 weeks prior to Visit 1. In addition, any topical ophthalmic preparations were disallowed for 1 week prior to Visit 1 and throughout the study. Contact lens wearers were required to discontinue use for at least 3 days prior to the conjunctival biopsy procedure and for the duration of the study.

At all study visits, subjects were queried for adverse events (AEs).

\section{Enrollment}

Subjects were screened for enrollment at Visit 1 only after providing written informed consent. Subjects' demographic data, medical history, and medication history was then recorded. BCVA was measured using the ETDRS chart. An undilated biomicroscopy slit-lamp exam was performed to examine both eyes for tissue abnormalities or other ocular disease. The eye with worse visual acuity (VA) was selected for biopsy. If a subject had equivalent VA in both eyes, the biopsy site was selected as the nondominant eye as determined by the subject. Eligible subjects were randomized in a 1:1:1 ratio to receive one dose of besifloxacin, moxifloxacin, or gatifloxacin. Each subject was also randomized to one biopsy collection interval of $15 \pm 1$ minutes, $30 \pm 1$ minutes, 2 hours \pm 5 minutes, 6 hours \pm 15 minutes, 12 hours \pm 15 minutes, or 24 hours \pm 15 minutes after drug instillation. This randomization scheme created a total of 18 treatment cohorts ( $n=6$ per cohort), each assigned a unique combination of antibiotic and biopsy collection time. In order to maintain a balance in the treatment groups, subjects who were discontinued prior to biopsy were replaced by the next subject enrolled.

\section{Treatment and biopsy}

The 15-minute, 30-minute, 2-hour, and 6-hour groups received treatment and underwent conjunctival biopsy at a single visit (Visit 2, Day 0). The 12-hour and 24-hour groups received treatment at Visit $2 \mathrm{a}$ (Day 0 ) before returning for the biopsy procedure at Visit 2 (Day 1). Each subject received one dose of besifloxacin (Besivance ${ }^{\mathbb{R}}$; Bausch and Lomb, Inc., Rochester, New York, USA), moxifloxacin (Vigamox ${ }^{\circledR}$; Alcon Laboratories, Inc., Fort Worth, Texas, USA), or gatifloxacin (Zymar ${ }^{\circledR}$; Allergan, Inc., Irvine, California, USA) in the biopsy eye only. At Visits $2 \mathrm{a}$ and 2 , subjects were asked to provide any updates to their medical and medication histories. BCVA was measured and a slit-lamp exam was performed prior to drug instillation. For subjects in the 12- and 24-hour cohorts, BCVA and slit-lamp exams were performed a second time at Visit 2 prior to biopsy.

Prior to the biopsy procedure, the study eye was verbally confirmed. A 5\% povidone-iodine (P-I) solution was instilled in the study eye after periocular skin was sterilized with $10 \%$ P-I. The investigator then removed two tissue samples from the nasal and temporal regions of the inferior palpebral conjunctiva. Samples were weighed and immediately transferred to a freezer at $-80^{\circ} \mathrm{C}$. Samples were later repackaged on dry ice and shipped to Bausch and Lomb, Inc. (Rochester, New York, USA) for analysis.

After the biopsy procedure at Visit 2, subjects were given loteprednol etabonate $0.5 \%$ with tobramycin $0.3 \%$ Zylet $^{\circledR}$; Bausch and Lomb, Rochester, New York, USA) to use 4 times a day for 5 days to prevent infection and inflammation at the biopsy site.

Subjects were required to return for follow-up at Visit 3 (Day $1 \pm 1$ ) and Visit 4 (Day $6 \pm 1$ ). Medical and medication history updates were collected prior to BCVA measurement and slit-lamp exam. Per protocol, expected signs and symptoms of the biopsy procedure (eg, mild ocular pain, mild edema at or around the biopsy site, mild bleeding at the biopsy site) were not classified as adverse events for this study. 


\section{Conjunctival concentration analyses}

PK analyses were performed on the modified intent-to-treat (mITT) population $(\mathrm{N}=108)$. Conjunctival biopsy samples were analyzed for concentrations of besifloxacin, moxifloxacin, and gatifloxacin using liquid chromatography-tandem mass spectrometry (LC-MS/MS) with a Sciex API 4000 triple quadrupole mass spectrometer (Applied Biosystems, Foster City, California, USA) with a TurboIonSpray ${ }^{\circledR}$ source. An XBridge ${ }^{\mathrm{TM}}$ C18 $(2.1 \times 50 \mathrm{~mm}, 3.5-\mu \mathrm{m}$ particle size) column (Waters Corporation, Milford, Massachusetts, USA) with a mobile phase of a 20/80 (v/v) mixture of acetonitrile/water $+0.2 \%$ formic acid was used. The lower limit of quantitation (LLOQ) for each analyte was $17.9 \mathrm{ng} / \mathrm{g}$ (ng of drug per gram of tissue).

\section{Statistical analyses}

PK calculations were performed using SAS version 9.1 (SAS Institute, Inc., Cary, North Carolina, USA). Concentrations that were below the limit of quantitation (BLQ) were assigned a value of $8.95 \mathrm{ng} / \mathrm{g}$, which is equal to one-half the value of the LLOQ $(17.9 \mathrm{ng} / \mathrm{g})$. This rationale was employed because it is improbable that the drug concentrations were equal to zero in these samples, while the results of the analysis confirmed that the concentrations were less than $17.9 \mathrm{ng} / \mathrm{g}$.

\section{Results}

The study included a total of 119 participants, including 46 males and 73 females (Table 2). Subjects ranged from 18 to 74 years of age, with a mean age of 42.6 years. Approximately $9 \%(11 / 119)$ of the study subjects were non-white. Demographic characteristics were similar between treatment groups. Brown was the most common iris color overall (in $55 / 119$, or $46.2 \%$ of subjects) and within each of the three treatment groups.

Out of the 119 subjects enrolled, a total of 108 underwent biopsy (Table 3; Figure 1). Eleven (11) subjects (9.2\% of those enrolled) were discontinued from the study prior to biopsy: 3 because of adverse events, 2 after withdrawing consent, and the remaining 6 for various reasons. The mITT population consisted of 108 subjects and was used for the primary $\mathrm{PK}$ analysis. The safety population, which included all subjects that received at least one dose of medication, consisted of 109 subjects. In total, 36 subjects per treatment arm completed the study.

\section{Biopsy}

One hundred nine (109) subjects were dosed. Of those, 108 underwent biopsy. One subject received a dose of

Table 2 Demographics of intent-to-treat (ITT) population

\begin{tabular}{|c|c|c|c|c|}
\hline & Besifloxacin $0.6 \% \mathrm{~N}=38$ & Moxifloxacin $0.5 \% \mathrm{~N}=38$ & Gatifloxacin $0.3 \% N=43$ & Total $\mathbf{N}=119$ \\
\hline \multicolumn{5}{|l|}{ Age (years) } \\
\hline Mean (SD) & $42.5(14.3)$ & $40.5(15.0)$ & $44.6(17.0)$ & $42.6(15.5)$ \\
\hline Range & $20-66$ & $18-68$ & $18-74$ & I8-74 \\
\hline \multicolumn{5}{|l|}{ Gender } \\
\hline Male & $17(44.7 \%)$ & $12(34.2 \%)$ & $16(37.2 \%)$ & $46(38.7 \%)$ \\
\hline Female & $21(55.3 \%)$ & $25(65.8 \%)$ & 27 (62.8\%) & $73(61.3 \%)$ \\
\hline \multicolumn{5}{|l|}{ Ethnicity } \\
\hline Hispanic or Latino & $3(7.9 \%)$ & $5(13.2 \%)$ & $2(4.7 \%)$ & $10(8.4 \%)$ \\
\hline Not Hispanic or Latino & $35(92.1 \%)$ & $33(86.8 \%)$ & $4 \mathrm{l}(95.3 \%)$ & 109 (91.6\%) \\
\hline \multicolumn{5}{|l|}{ Race } \\
\hline American Indian/Alaskan Native & I (2.6\%) & $0(0.0 \%)$ & $0(0.0 \%)$ & I (0.8\%) \\
\hline Asian & $0(0.0 \%)$ & I (2.6\%) & I (2.3\%) & $2(1.7 \%)$ \\
\hline Black/African-American & I (2.6\%) & $0(0.0 \%)$ & $0(0.0 \%)$ & I (0.8\%) \\
\hline White & $35(92.1 \%)$ & 34 (89.5\%) & 39 (90.7\%) & $108(90.8 \%)$ \\
\hline Other & I (2.6\%) & $3(7.9 \%)$ & $3(7.0 \%)$ & 7 (5.9\%) \\
\hline \multicolumn{5}{|l|}{ Iris color } \\
\hline Blue & $10(26.3 \%)$ & 7 (I8.4\%) & $10(23.3 \%)$ & $27(22.7 \%)$ \\
\hline Brown & I5 (39.5\%) & 19 (50.0\%) & 21 (28.8\%) & 55 (46.2\%) \\
\hline Green & $2(5.3 \%)$ & $4(10.5 \%)$ & 5 (II.6\%) & II (9.2\%) \\
\hline Hazel & II (28.9\%) & 8 (21.1\%) & 7 (I6.3\%) & $26(21.8 \%)$ \\
\hline
\end{tabular}

Notes: Subject-reported races designated as 'Other' include: Native Indian/Latino (I), Spanish (I), Polish (I), Mulatto (I), Hispanic (I), and Puerto Rican (2). Abbreviation: SD, standard deviation. 
Table 3 Disposition of enrolled subjects

\begin{tabular}{|c|c|c|c|c|}
\hline & Besifloxacin $0.6 \%$ & Moxifloxacin $0.5 \%$ & Gatifloxacin $0.3 \%$ & Total \\
\hline Randomized (ITT) & $38(100 \%)$ & $38(100 \%)$ & $43(100 \%)$ & $119(100 \%)$ \\
\hline Completed (mITT) & $36(94.7 \%)$ & $36(94.7 \%)$ & $36(83.7 \%)$ & $108(90.8 \%)$ \\
\hline Safety population & $38(100 \%)$ & $36(94.7 \%)$ & 37 (86.0\%) & III (93.3\%) \\
\hline Per-protocol population & 35 (92.1\%) & 36 (94.7\%) & 35 (8I.4\%) & $106(89.1 \%)$ \\
\hline Discontinued & $2(5.3 \%)$ & $2(5.3 \%)$ & 7 (16.3\%) & II (9.2\%) \\
\hline Adverse event & I $(2.6 \%)$ & $0(0.0 \%)$ & $2(4.7 \%)$ & $3(3.5 \%)$ \\
\hline Consent withdrawn & $0(0.0 \%)$ & $0(0.0 \%)$ & $2(4.7 \%)$ & $2(1.7 \%)$ \\
\hline Investigator’s decision & $0(0.0 \%)$ & I (2.6\%) & $0(0.0 \%)$ & I (0.8\%) \\
\hline Protocol violation & I (2.6\%) & I (2.6\%) & $0(0.0 \%)$ & $2(1.7 \%)$ \\
\hline Administrative reasons & $0(0.0 \%)$ & $0(0.0 \%)$ & $2(4.7 \%)$ & $2(1.7 \%)$ \\
\hline Pregnancy & $0(0.0 \%)$ & $0(0.0 \%)$ & I (2.3\%) & I (0.8\%) \\
\hline
\end{tabular}

a Subject had a negative pregnancy test at Visit I, but reported a positive pregnancy test prior to Visit 2a. The subject was discontinued immediately and did not receive any test medications.

Abbreviations: ITT, intent-to-treat population; mITT, modified intent-to-treat population.

besifloxacin but did not undergo biopsy because the preparation work for the biopsy was unintentionally completed 1 hour prior to the scheduled time. As a result, the subject was discontinued prior to biopsy. All 108 biopsy specimens provided sufficient tissue mass for the drug level analysis. A nasal specimen was not collected for one subject in the moxifloxacin 15-minute cohort; however, that subject's temporal section provided enough tissue for analysis. One biopsy in the 24-hour besifloxacin cohort was performed 12 minutes out-of-window, at 24 hours and 27 minutes after drug instillation. However, this sample was still included in the tissue analysis because it was not substantially out-of-window.

\section{Pharmacokinetic analyses}

Mean and median conjunctival drug concentrations for the 18 treatment cohorts at each collection time are provided in Table 4 . The maximum mean concentration $\left(\mathrm{C}_{\max }\right)$ occurred at 15 minutes for all three compounds. The $\mathrm{C}_{\max }$ for moxifloxacin $(10.7 \mu \mathrm{g} / \mathrm{g})$ was more than double that of gatifloxacin $(4.03 \mu \mathrm{g} / \mathrm{g})$ and besifloxacin $(2.30 \mu \mathrm{g} / \mathrm{g})$. Whereas concentrations at 30 minutes for moxifloxacin and gatifloxacin were approximately half those of the respective 15 minute time-points, the mean concentration of besifloxacin remained stable between 15 minutes $(2.30 \pm 1.42 \mu \mathrm{g} / \mathrm{g})$ and 30 minutes $(2.29 \pm 1.30 \mu \mathrm{g} / \mathrm{g})$. For all three FQs, the mean concentrations declined with each successive time-point.

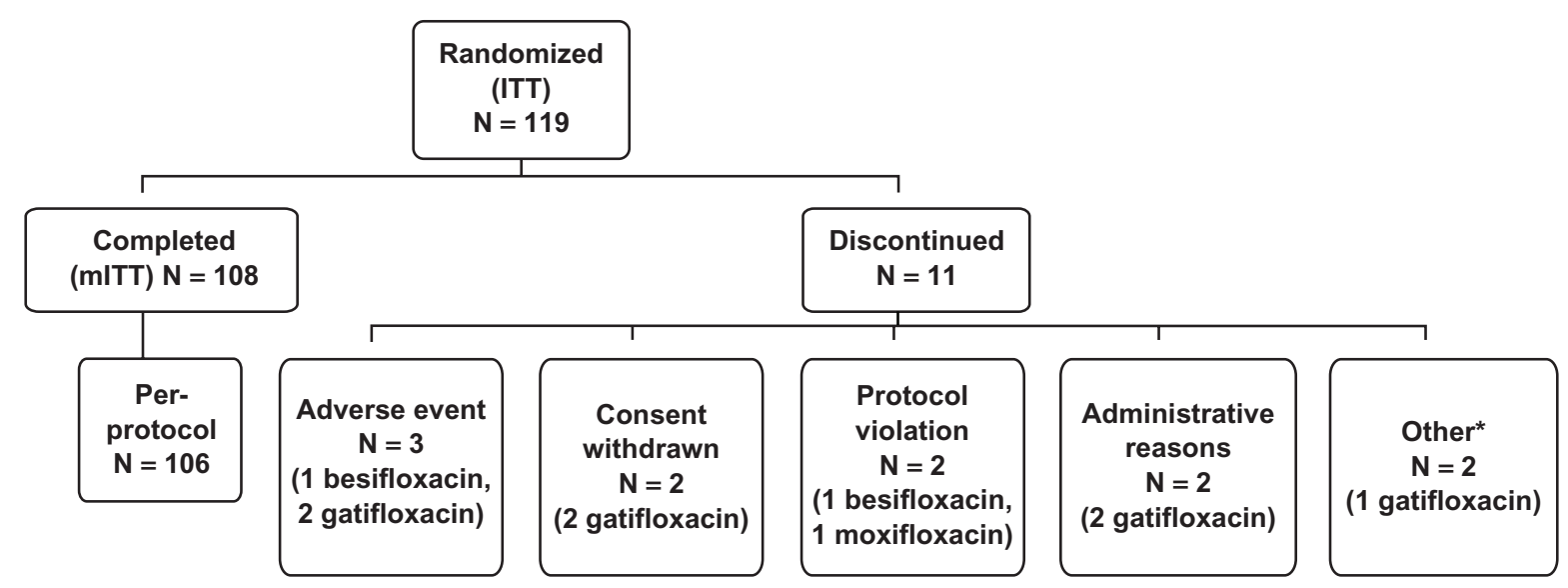

Figure I Disposition of enrolled subjects.

ancludes I subject discontinued due to investigator's decision and I subject discontinued due to pregnancy. In the latter case, the subject had a negative pregnancy test at Visit I, but reported that she had a positive pregnancy test prior to Visit 2a. The subject was discontinued immediately before the scheduled Visit 2a and did not receive any test medications.

Abbreviations: ITT, intent-to-treat population; mITT, modified intent-to-treat population. 
Table 4 Mean and median fluoroquinolone concentrations in conjunctival tissue (mITT population)

\begin{tabular}{|c|c|c|c|c|}
\hline & & $\begin{array}{l}\text { Besifloxacin } \\
0.6 \%(\mu \mathrm{g} / \mathrm{g}) \\
\mathrm{N}=\mathbf{3 6}\end{array}$ & $\begin{array}{l}\text { Moxifloxacin } \\
0.5 \%(\mu \mathrm{g} / \mathrm{g}) \\
\mathrm{N}=\mathbf{3 6}\end{array}$ & $\begin{array}{l}\text { Gatifloxacin } \\
0.3 \%(\mu g / g) \\
\mathbf{N}=\mathbf{3 6}\end{array}$ \\
\hline \multirow[t]{2}{*}{15 minutes } & Mean (SD) & $2.30(1.42)$ & $10.7(5.89)$ & $4.03(3.84)$ \\
\hline & Median & 1.65 & 9.23 & 3.04 \\
\hline \multirow[t]{2}{*}{30 minutes } & Mean (SD) & $2.29(1.30)$ & $4.04(4.16)$ & $2.76(0.737)$ \\
\hline & Median & 1.75 & 2.80 & 2.61 \\
\hline \multirow[t]{2}{*}{2 hours } & Mean (SD) & $0.418(0.28 I)$ & $0.845(0.440)$ & $0.448(0.284)$ \\
\hline & Median & 0.442 & 0.917 & 0.444 \\
\hline \multirow[t]{2}{*}{6 hours } & Mean (SD) & $0.324(0.355)$ & $0.228(0.162)$ & $0.162(0.205)$ \\
\hline & Median & 0.161 & 0.184 & 0.0936 \\
\hline \multirow[t]{2}{*}{12 hours } & Mean (SD) & $0.122(0.196)$ & $0.146(0.123)$ & $0.0586(0.0675)$ \\
\hline & Median & 0.0447 & 0.134 & 0.0311 \\
\hline \multirow[t]{2}{*}{24 hours } & Mean (SD) & $0.0338(0.0262)$ & $0.0248(0.0309)$ & $0.0186(0.0133)$ \\
\hline & Median & 0.0309 & 0.00895 & 0.0127 \\
\hline
\end{tabular}

Notes: Biopsies were performed at $15 \pm 1$ minute, $30 \pm 1$ minute, 2 hours \pm 5 minutes, 6 hours \pm 15 minutes, 12 hours \pm 15 minutes, and 24 hours \pm 15 minutes. Biopsy samples containing a concentration of drug below the lower limit of quantitation (LLOQ = $17.9 \mathrm{ng} / \mathrm{g}$ ) were assigned a value equal to one-half the LLOQ (8.95 $\mathrm{ng} / \mathrm{g}$ ).

Abbreviations: mITT, modified intent-to-treat population ( $N=108)$; $S D$, standard deviation.

In 9 out of the 108 biopsy specimens, the drug concentration was below the LLOQ. All of these BLQ samples were from the 24-hour collection time. These specimens were assigned a value of $8.95 \mathrm{ng} / \mathrm{g}$, per the rationale articulated in the Methods section. The besifloxacin group had the greatest number of subjects with quantifiable amounts of drug in the tissue at 24 hours $(4 / 6)$, compared with the gatifloxacin group (3/6 subjects) and the moxifloxacin group (2/6 subjects). At 24 hours post-instillation, the mean concentrations were $0.034 \pm$ $0.026 \mu \mathrm{g} / \mathrm{g}$ for besifloxacin, $0.025 \pm 0.031 \mu \mathrm{g} / \mathrm{g}$ for moxifloxacin, and $0.019 \pm 0.013 \mu \mathrm{g} / \mathrm{g}$ for gatifloxacin. Because of the relatively small sample size at the 24-hour collection and the prevalence of BLQ samples in this collection group, the apparent differences in concentrations at 24 hours should be interpreted with caution. To aid in this assessment, the results for each individual sample in the 24-hour collection group is presented in Figure 2.

A concentration-time curve was constructed using the mean concentration data for each FQ (Figure 3 ). The total area-under-the-curve from time of dosing to 24 hours post-instillation $\left(\mathrm{AUC}_{0-24 \mathrm{~h}}\right)$ was then calculated for each drug (Table 5). The $\mathrm{AUC}_{0-24 \mathrm{~h}}$ for moxifloxacin, $11.1 \mu \mathrm{g} / \mathrm{g}$, was almost 2 times greater than the $\mathrm{AUC}_{0-24 \mathrm{~h}}$ for besifloxacin $(6.65 \mu \mathrm{g} / \mathrm{g})$ and for gatifloxacin $(6.10 \mu \mathrm{g} / \mathrm{g})$. However, the same concentration-time curve reveals that besifloxacin had the longest mean residence time (MRT) in the conjunctiva, at 4.7 hours.

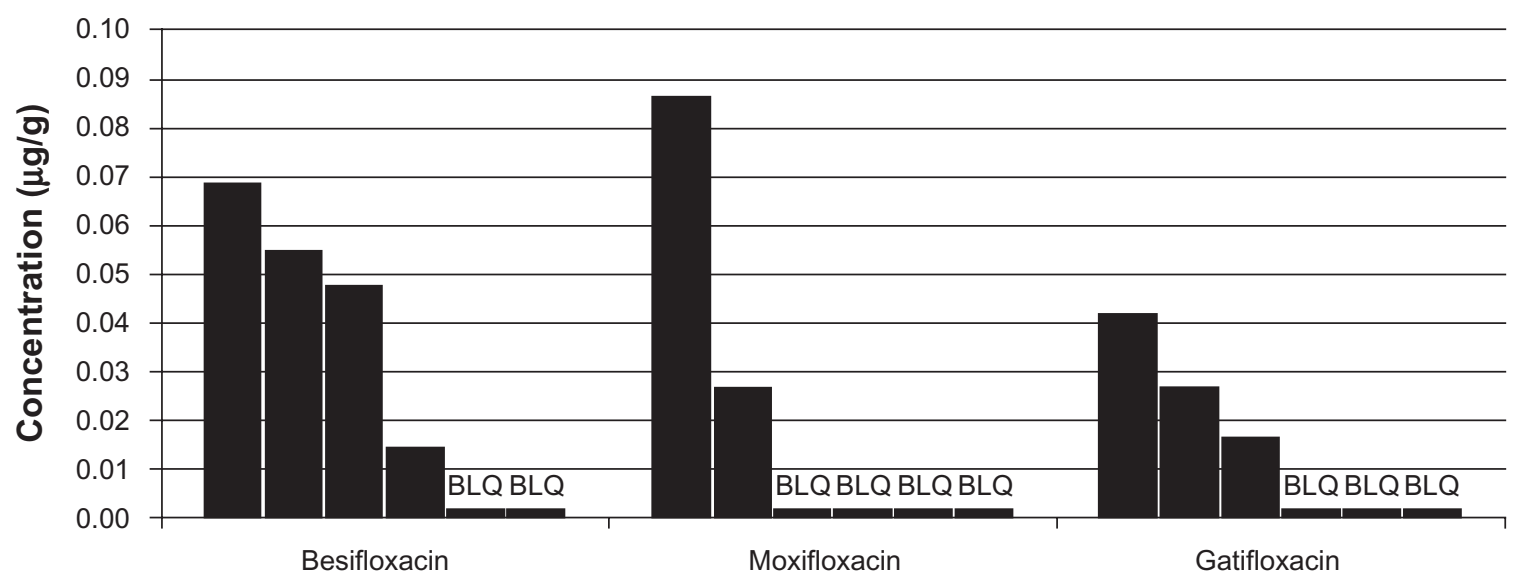

Figure 2 Conjunctival fluoroquinolone concentrations ( $\mu \mathrm{g} / \mathrm{g})$ in individual subjects at 24 hours (mITT population).

Abbreviations: $\mathrm{mlTT}$, modified intent-to-treat population $(\mathrm{N}=108)$; BLQ, concentration below the limit of quantitation $(17.9 \mathrm{ng} / \mathrm{g})$. 


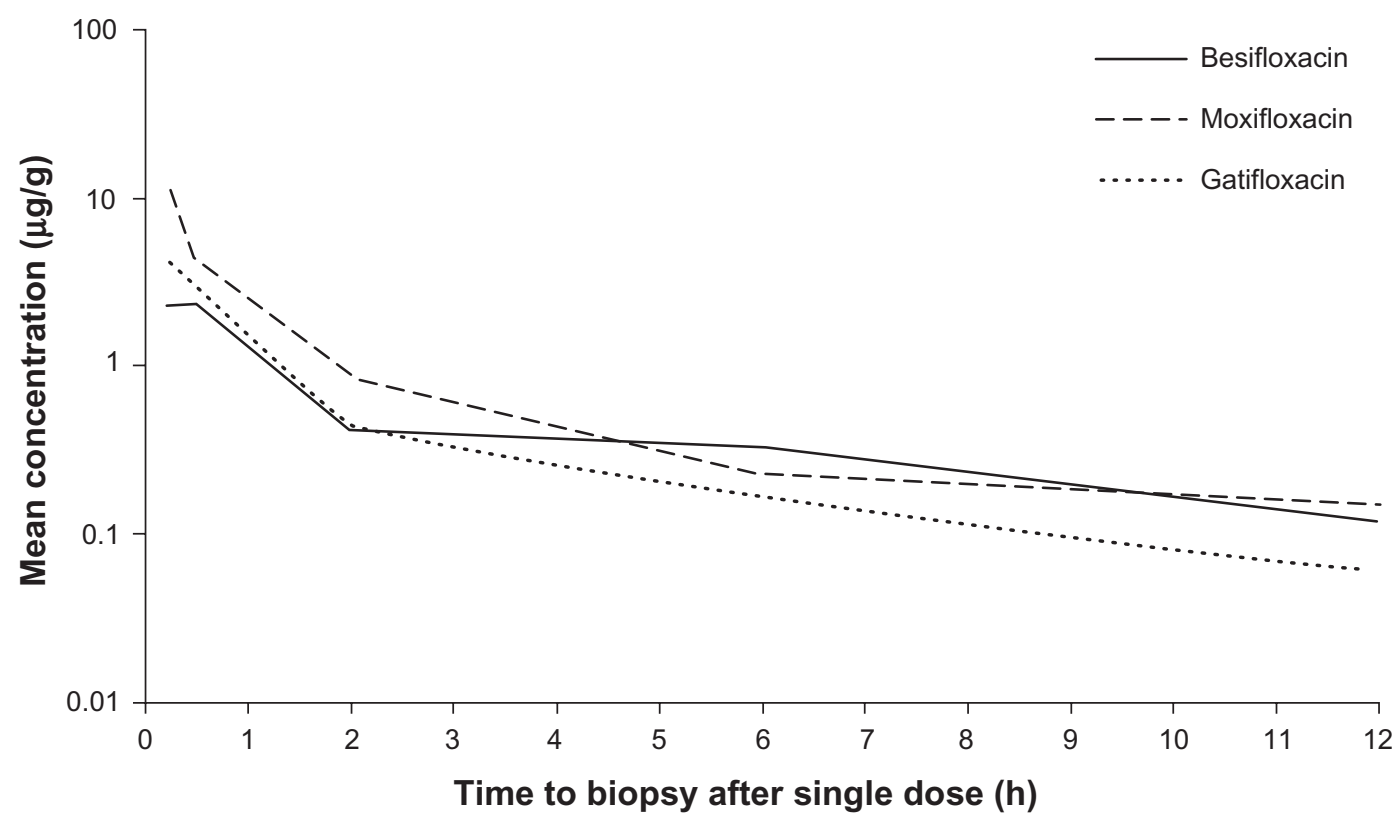

Figure 3 Mean fluoroquinolone concentration-time curves in conjunctiva (mITT population).

Notes: Concentration data for biopsies performed at 24 hours are presented as a separate figure (Figure 3 ).

Abbreviation: $\mathrm{mlTT}$, modified intent-to-treat population $(\mathrm{N}=108)$.

\section{Safety outcomes}

No serious AEs (SAEs) occurred in this study. There were 11 treatment-related AEs that were mild or moderate in nature (Table 6). Overall, $9.2 \%$ of subjects in the safety population $(10 / 109)$ experienced a treatment-related AE. There were 4 AEs in the moxifloxacin group (11.1\% of subjects), 4 AEs in the besifloxacin group (10.8\% of subjects), and 2 AEs in the gatifloxacin group (5.6\% of subjects). The most commonly reported adverse events were ocular pain $(\mathrm{N}=5)$ and headache $(\mathrm{N}=2)$.

\section{Discussion}

Although multiple topical ocular antibiotics are available, each has unique pharmacokinetic (PK) and pharmacodynamic (PD) properties that influence its therapeutic value. The aim of the present study was to characterize the human conjunctival PK properties of $3 \mathrm{FQs}$ that have been approved

Table 5 Area-under-the-curve over 24 hours $\left(\mathrm{AUC}_{0-24 \mathrm{~h}}\right)$ and mean residence time (MRT) for fluoroquinolones in conjunctiva

\begin{tabular}{|c|c|c|}
\hline Fluoroquinolone & $\operatorname{AUC}_{0-24 \mathrm{~h}}(\mu \mathrm{g} \cdot \mathrm{h} / \mathrm{g})$ & MRT $(h)^{\mathrm{a}}$ \\
\hline Besifloxacin & 6.65 & 4.7 \\
\hline Moxifloxacin & $\mathrm{II} . \mathrm{I}$ & 3.0 \\
\hline Gatifloxacin & 6.10 & 2.9 \\
\hline
\end{tabular}

aMean residence time (MRT) corresponds to 1.44 multiplied by the half-life (in hours) of the drug. MRT was calculated using the equation: MRT $=$ AUMC/AUC (AUMC = area-under-the-first-moment-curve; $A \cup C=$ area-under-the-curve). for the treatment of bacterial conjunctivitis in the US within the past decade. Because FQs are concentration-dependent antibiotics, their microbial eradication rates depend upon the concentration that they achieve at the site of infection. The conjunctival biopsy model provides a standardized method for assessing drug tissue concentrations that are relevant to bacterial conjunctivitis. The model is particularly useful for analyzing drug concentrations at multiple time intervals after drug instillation.

Several conjunctival tissue penetration studies have previously been conducted in humans. ${ }^{15,16,18}$ Aihara et al compared levofloxacin, gatifloxacin, and moxifloxacin levels in diseased pterygium tissue collected at 10, 30, and 45 minutes after a single dose. They found that the concentration of moxifloxacin was higher than the other FQs at all sample times, with a $\mathrm{C}_{\max }$ of $116.7 \pm 28.9 \mu \mathrm{g} / \mathrm{g}$ at 10 minutes after instillation. At 30 minutes, the mean concentrations of levofloxacin, gatifloxacin, and moxifloxacin were $11.3 \pm 2.3 \mu \mathrm{g} / \mathrm{g}, 11.8 \pm 3.9 \mu \mathrm{g} / \mathrm{g}$, and $19.0 \pm 6.3 \mu \mathrm{g} / \mathrm{g}$, respectively. All of these values are markedly higher than the mean concentrations observed in the present study. However, in the Aihara study, BAK-free formulations of levofloxacin and gatifloxacin were used, which are not available in the US. It is unknown how this difference, as well as the collection of diseased pterygium, as opposed to healthy conjunctiva tissue, affected their results. Wagner et al detected a trend similar to the one found by Aihara et al yielding comparable levofloxacin and gatifloxacin concen- 
Table 6 Treatment-related adverse events (AEs) occurring in the safety population

\begin{tabular}{lllll}
\hline & Besifloxacin & Moxifloxacin & Gatifloxacin & Total \\
& $\mathbf{0 . 6 \%} \mathbf{N}=\mathbf{3 7}$ & $\mathbf{0 . 5 \%} \mathbf{N}=\mathbf{3 6}$ & $\mathbf{0 . 3 \%} \mathbf{N}=\mathbf{3 6}$ & $\mathbf{N}=\mathbf{1 0 9}$ \\
\hline Ocular pain & $3(8.1 \%)$ & $\mathrm{I}(2.8 \%)$ & $\mathrm{I}(2.8 \%)$ & $\mathrm{5}(4.6 \%)$ \\
Foreign body sensation & $0(0.0 \%)$ & $0(0.0 \%)$ & $\mathrm{I}(2.8 \%)$ & $\mathrm{I}(0.9 \%)$ \\
Blurred vision & $\mathrm{I}(2.7 \%)$ & $0(0.0 \%)$ & $0(0.0 \%)$ & $\mathrm{I}(0.9 \%)$ \\
Dysgeusia & $0(0.0 \%)$ & $\mathrm{I}(2.8 \%)$ & $0(0.0 \%)$ & $\mathrm{I}(0.9 \%)$ \\
Headache & $\mathrm{I}(2.7 \%)$ & $\mathrm{I}(2.8 \%)$ & $0(0.0 \%)$ & $\mathrm{I}(\mathrm{I})$ \\
Procedural site reaction & $0(0.0 \%)$ & $\mathrm{I}(2.8 \%)$ & $0(0.0 \%)$ & \\
\hline
\end{tabular}

Notes: Includes AEs determined by the investigator to have a possible, probable, or definite relationship to the study medication.

trations $(2.34 \mu \mathrm{g} / \mathrm{g}$ and $2.54 \mu \mathrm{g} / \mathrm{g}$, respectively) in healthy conjunctiva collected at 20 minutes after a single dose. The concentration of moxifloxacin $(18.0 \mu \mathrm{g} / \mathrm{g})$ was relatively greater. Conjunctival samples collected after a single administration in the Torkildsen et al study yielded a mean moxifloxacin concentration of $1.92 \pm 2.03 \mu \mathrm{g} / \mathrm{g}$ at 30 minutes, a value that is nearly an order of magnitude smaller than what was detected in the other two studies. The results from the present study (eg, mean concentration of moxifloxacin at 30 minutes: $4.04 \pm 4.16 \mu \mathrm{g} / \mathrm{g}$ ) lie somewhere between the concentrations detected by Torkildsen et al and those detected in the other two studies.

In this study, all three FQs tested had similar PK profiles; their concentrations peaked early and declined to a low level by the time 24 hours had elapsed. The $\mathrm{C}_{\max }$ achieved by moxifloxacin $(10.7 \mu \mathrm{g} / \mathrm{g})$ was approximately 2 - to 5 -fold higher than the $\mathrm{C}_{\max }$ of besifloxacin $(2.30 \mu \mathrm{g} / \mathrm{g})$ and of gatifloxacin $(4.03 \mu \mathrm{g} / \mathrm{g})$. Moxifloxacin has a pyrrolo-pyridine base that makes it more lipophilic relative to other FQs; this difference has been proposed as the principal reason for moxifloxacin's preferential absorption into ocular tissue. ${ }^{19}$ Although the $\mathrm{C}_{\max }$ for moxifloxacin was higher, the $\mathrm{AUC}_{0-24}$ for moxifloxacin was less than double the $\mathrm{AUC}_{0-24}$ for the two other FQs (Table 5). Moxifloxacin reached a relatively high concentration at 15 minutes (mean: $10.7 \pm 5.89 \mu \mathrm{g} / \mathrm{g}$ ), but its presence in the tissue declined $62.1 \%$ by 30 minutes $(4.04 \pm 4.16 \mu \mathrm{g} / \mathrm{g})$. In contrast, the declines in mean gatifloxacin and besifloxacin concentrations from 15 to 30 minutes were $31.5 \%$ and $<0.1 \%$, respectively. When median concentrations are evaluated, besifloxacin was the only FQ tested whose concentration increased from 15 minutes $(1.65 \mu \mathrm{g} / \mathrm{g})$ to 30 minutes $(1.75 \mu \mathrm{g} / \mathrm{g})$.

Large variations occurred between concentration values within the same cohort. Most standard deviations (SDs) in mean concentration ranged from $50 \%$ to $100 \%$ of the mean value. A similar trend was detected in the Torkildsen et al study in 2008. Individual variations in conjunctival tissue and/or tear flow may be responsible. The sample size for this study $(\mathrm{n}=108)$ was large, but treatment cohort sizes were small $(n=6)$. Cohort sizes could be increased in future studies to investigate reasons behind the differential absorption of drug between individuals.

Besifloxacin demonstrated the most stable behavior in conjunctival tissue, having the greatest MRT of 4.7 hours. This finding may be attributable to differences in the vehicles between besifloxacin and the other two FQs. The besifloxacin formulation used in the present study contains DuraSite ${ }^{\circledR}$ (InSite Vision, Inc., Alameda, California, USA), a proprietary polymeric mucoadhesive delivery system that has been shown to enhance drug residence time on the ocular surface. ${ }^{20}$

The ratio of antibiotic concentration to MIC is another important contributor to fluoroquinolones' microbiologic efficacy. For fluoroquinolones, the $\mathrm{AUC}_{0-24 \mathrm{~h}}: \mathrm{MIC}_{90}$ ratio is the pharmacodynamic parameter that best correlates with clinical efficacy. ${ }^{11-14}$ Furthermore, the greater the $\mathrm{AUC}_{0-24 \mathrm{~h}}$ : $\mathrm{MIC}_{90}$ ratio, the less likely antibiotic resistance is to emerge among bacteria. ${ }^{21}$ Many non-ocular studies have established $\mathrm{AUC}_{0-24} \mathrm{~h}: \mathrm{MIC}_{90}$ breakpoints that describe the level of dosing needed to promote clinical success. For example, a human study on respiratory tract infections caused by $S$. pneumoniae found that treatment with gatifloxacin at an $\mathrm{AUC}_{0-24 \mathrm{~h}}: \mathrm{MIC}_{90}$ ratio $\geq 33.7$ predicted clinical resolution of infection. ${ }^{12}$ There are limited studies of the significance of AUC:MIC ratios in ocular infection. In 2003, Wilhelmus performed a study of bacterial keratitis patients $(\mathrm{N}=391)$ receiving ciprofloxacin drops. Using an estimated $\mathrm{AUC}_{0-24 \mathrm{~h}}$ value of $68.5 \mu \mathrm{g} / \mathrm{mL}$ and an $\mathrm{MIC}_{90}$ value specific to each patient's bacterial isolate, Wilhelmus plotted patient values for $\mathrm{AUC}_{0-24} \mathrm{~h}$ : $\mathrm{MIC}_{90}$ against clinical resolution. The breakpoint for $90 \%$ predicted clinical improvement was an $\mathrm{AUC}_{0-24 \mathrm{~h}}: \mathrm{MIC}_{90}$ ratio of $151 .{ }^{22}$ However, the study did not account for individual variation in the concentration-time curve, which our study 
suggests to be significant based on the large SD values for drug concentrations in each treatment cohort (Table 4). The authors are unaware of any pharmacodynamic studies that establish therapeutic $\mathrm{AUC}_{0-24 \mathrm{~h}}: \mathrm{MIC}_{90}$ breakpoints for gatifloxacin, moxifloxacin, or besifloxacin in ocular infection.

In this PK study, the quantity of moxifloxacin $\left(\mathrm{AUC}_{0-24 \mathrm{~h}}=11.1 \mu \mathrm{g} \bullet \mathrm{h} / \mathrm{g}\right)$ delivered to the tissue over the course of 24 hours was almost twice the amount of besifloxacin $\left(\mathrm{AUC}_{0-24 \mathrm{~h}}=6.65 \mu \mathrm{g} \bullet \mathrm{h} / \mathrm{g}\right)$ or gatifloxacin $\left(\mathrm{AUC}_{0-24 \mathrm{~h}}=6.10 \mu \mathrm{g} \bullet \mathrm{h} / \mathrm{g}\right.$ ) delivered. As discussed previously, the potential clinical significance of this PK data is only relevant when one also compares the $\mathrm{MIC}_{90}$ values for these agents against specific pathogens. In theory, based on the $\mathrm{AUC}_{0-24 \mathrm{~h}}$ values observed in this study, moxifloxacin would offer a potential therapeutic advantage in the conjunctiva in cases where the $\mathrm{MIC}_{90}$ value for moxifloxacin was up to 2-fold higher than the $\mathrm{MIC}_{90}$ for besifloxacin or gatifloxacin. In contrast, the available PK data indicate that the potential therapeutic efficacy of besifloxacin or gatifloxacin would be better than moxifloxacin in cases where the $\mathrm{MIC}_{90}$ value for moxifloxacin was more than 2-fold higher than the $\mathrm{MIC}_{90}$ for besifloxacin or gatifloxacin.

This relationship can be illustrated by using actual relevant $\mathrm{MIC}_{90}$ data to calculate $\mathrm{AUC}_{0-24 \mathrm{~h}}: \mathrm{MIC}_{90}$ ratios for each of the drugs. In this example, the ratios were calculated using $\mathrm{MIC}_{90}$ values for ocular isolates collected from very recent phase 3 studies of bacterial conjunctivitis in the US (Table 1; Figures 4-7). When $\mathrm{AUC}_{0-24 \mathrm{~h}}: \mathrm{MIC}_{90}$ ratios are calculated for the FQs against Staphylococcus organisms, besifloxacin has the greatest $\mathrm{AUC}_{0-24 \mathrm{~h}}: \mathrm{MIC}_{90}$ ratios and is the only FQ to achieve an $\mathrm{AUC}_{0-24 \mathrm{~h}}: \mathrm{MIC}_{90}$ ratio in excess of 100 for MSSA and MSSE (Figures 4 and 6). In the case of the methicillin-resistant $S$. epidermidis, the $\mathrm{AUC}_{0-24 \mathrm{~h}}: \mathrm{MIC}_{90}$ ratio for besifloxacin was 1.7 , compared with moxifloxacin and gatifloxacin ratios of 0.2 and 0.05 , respectively (Figure 7). A similar trend was observed for MRSA (Figure 5). In each instance, besifloxacin had the highest $\mathrm{AUC}_{0-24 \mathrm{~h}}: \mathrm{MIC}_{90}$ ratio for all Staphylococcus organisms. This suggests that one dose of besifloxacin may be more potent than a dose of gatifloxacin or moxifloxacin in treating an ocular Staphylococcus infection. While calculation of $\mathrm{AUC}_{0-24 \mathrm{~h}}: \mathrm{MIC}_{90}$ ratios using different $\mathrm{MIC}_{90}$ datasets may yield somewhat different results, this example illustrates the importance of considering PK and PD data in parallel. Furthermore, the microbiological data used in this example consists of $\mathrm{MIC}_{90}$ values that were determined for each fluoroquinolone under identical laboratory conditions, using a relevant and recently collected set of ocular isolates.
The illustrative example of $\mathrm{AUC}_{0-24 \mathrm{~h}}: \mathrm{MIC}_{90}$ ratios demonstrates that $\mathrm{AUC}_{0-24 \mathrm{~h}}: \mathrm{MIC}_{90}$ ratios were low (ie, <2) for resistant Staphylococcus organisms, regardless of the fluoroquinolone. However, a typical treatment regimen for bacterial conjunctivitis includes multiple doses per day, producing an $\mathrm{AUC}_{0-24 \mathrm{~h}}$ that would be greater than that observed in the present study following a single instillation. It is also important to consider the concentration of drug in the tear film. Gatifloxacin, moxifloxacin, and besifloxacin are present in tear film at concentrations that are markedly higher than the conjunctival concentrations measured in this study. The relative contribution of these high tear concentrations to the effective eradication of resistant bacteria has not been established. A previous PK study for besifloxacin revealed that the maximum besifloxacin concentrations in tear fluid after a single instillation were $610 \mu \mathrm{g} / \mathrm{g}$, which is approximately 265 -fold higher than the maximum besifloxacin concentration observed in conjunctiva in the present study. ${ }^{23}$ At 24 hours after a single dose, besifloxacin concentrations in tears were approximately 50 -fold higher than the conjunctival concentrations detected in this study. The concentration of drug in the tear may act synergistically with conjunctival drug concentration to contribute to the effective treatment of bacterial conjunctivitis. More work is needed to understand how drug concentrations in the tear and the conjunctiva affect the bacterial eradication in the human eye.

In general, all three FQs were well tolerated. Treatmentrelated AEs were not serious and were infrequent.

As concerns grow about resistant ocular infections, clinicians must pay special attention to an ocular antibiotic's

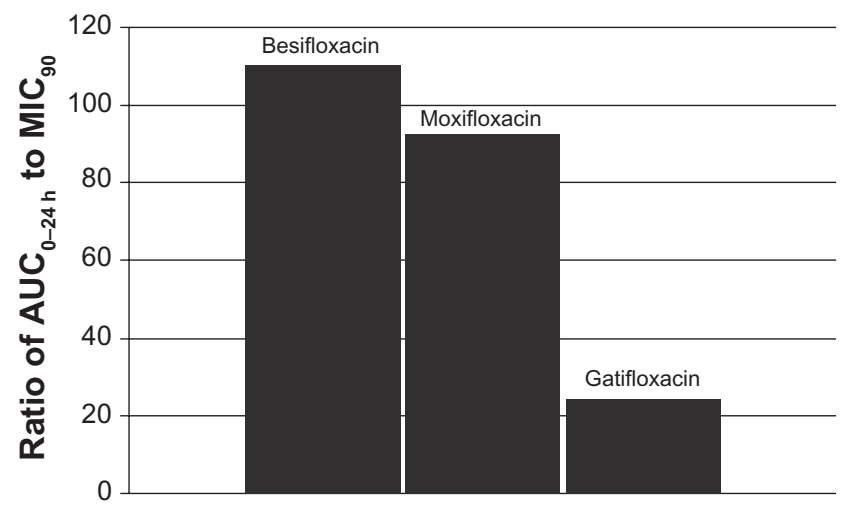

Figure 4 Ratio of fluoroquinolone $A U C_{0-24 h}$ in conjunctiva to the $M_{I C}$ for methicillin-sensitive $S$. aureus (MSSA) (mITT population). ${ }^{\text {. }}$

${ }^{\mathrm{a}} \mathrm{MIC}_{90}$ values were obtained from susceptibility testing of 144 methicillin-sensitive, ciprofloxacin-sensitive S. aureus isolates. The values were $0.06 \mu \mathrm{g} / \mathrm{mL}$ for besifloxacin, $0.12 \mu \mathrm{g} / \mathrm{mL}$ for moxifloxacin, and $0.25 \mu \mathrm{g} / \mathrm{mL}$ for gatifloxacin. ${ }^{7}$

Abbreviations: $\mathrm{AUC}_{0-24 \mathrm{~h}}$, area-under-the-curve, or the total amount of drug delivered to conjunctival tissue in I day following I dose; mITT, modified intent-to-treat population $(\mathrm{N}=108)$. 


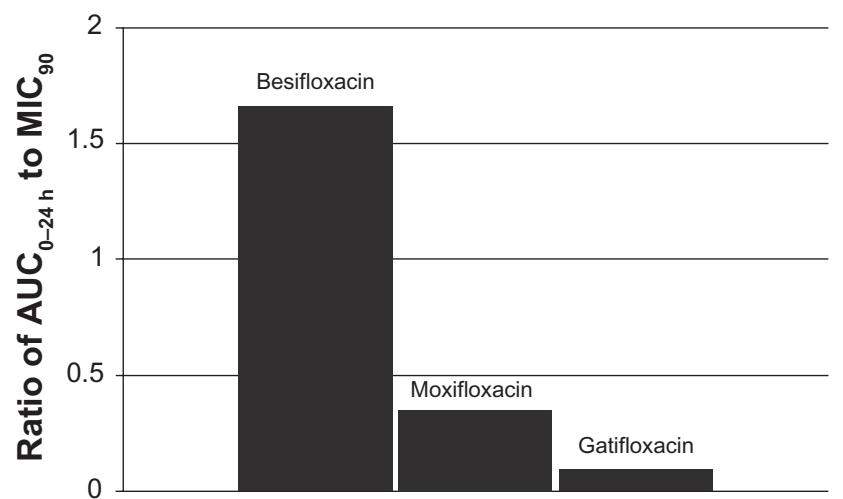

Figure 5 Ratio of fluoroquinolone $A U C_{0-24 h}$ in conjunctiva to the $M C_{90}$ for methicillin-resistant $S$. aureus (MRSA) (mITT population). ${ }^{\mathrm{a}}$

${ }^{a} M_{90}$ values were obtained from susceptibility testing of 81 methicillin-resistant, ciprofloxacin-resistant $S$. aureus isolates. The values were $4 \mu \mathrm{g} / \mathrm{mL}$ for besifloxacin, $32 \mu \mathrm{g} / \mathrm{mL}$ for moxifloxacin, and $64 \mu \mathrm{g} / \mathrm{mL}$ for gatifloxacin. ${ }^{24}$

Abbreviations: $\mathrm{AUC}_{0-24}$, area-under-the-curve, or the total amount of drug delivered to conjunctival tissue in I day following I dose; mITT, modified intent-to-treat population $(\mathrm{N}=108)$.

efficacy against multidrug-resistant organisms (MDROs). Susceptibility surveys such as the Ocular TRUST reveal an increasing incidence of MDROs in ocular infections. ${ }^{6}$ The resistance profile of ocular Staphylococcus bacteria should be considered when selecting a therapeutic agent for an ocular infection. The results from this study suggest that besifloxacin may be a preferable treatment, based on its achievement of the greatest $\mathrm{AUC}_{0-24}: \mathrm{MIC}_{90}$ ratio for resistant and non-resistant strains.

This single-dose, randomized study successfully characterized the human conjunctival PK of besifloxacin,

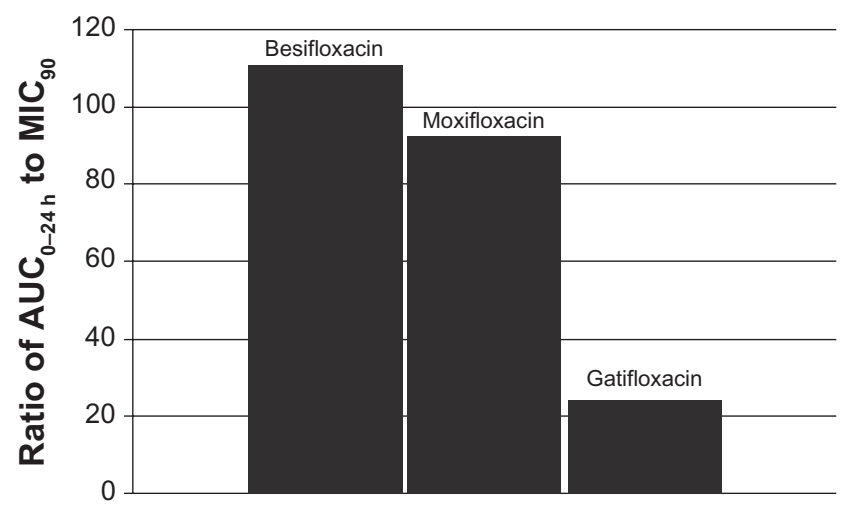

Figure 6 Ratio of fluoroquinolone $A \cup C_{0-24 h}$ in conjunctiva to the $M C_{90}$ for methicillinsensitive S. epidermidis (MSSE) (mITT population). ${ }^{\text {a }}$

${ }^{\mathrm{a}} \mathrm{MIC}_{90}$ values were obtained from susceptibility testing of 50 methicillin-sensitive, ciprofloxacin-sensitive $S$. epidermidis isolates. The values were $0.06 \mu \mathrm{g} / \mathrm{mL}$ for besifloxacin, $0.12 \mu \mathrm{g} / \mathrm{mL}$ for moxifloxacin, and $0.25 \mu \mathrm{g} / \mathrm{mL}$ for gatifloxacin. ${ }^{7}$

Abbreviations: $\mathrm{AUC}_{0-24}$, area-under-the-curve, or the total amount of drug delivered to conjunctival tissue in I day following I dose; mITT, modified intent-to-treat population $(\mathrm{N}=108)$.

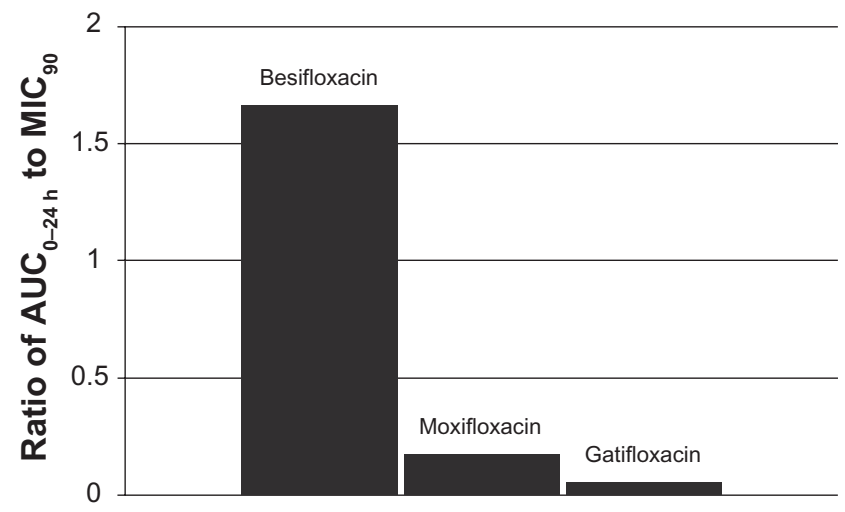

Figure 7 Ratio of fluoroquinolone $A \cup C_{0-24 h}$ in conjunctiva to the $M I C_{90}$ for methicillin-resistant $S$. epidermidis (MRSE) (mITT population). ${ }^{a}$

${ }^{a} \mathrm{MIC}_{90}$ values were obtained from susceptibility testing of 29 methicillin-resistant, ciprofloxacin-resistant $S$. epidermidis isolates. The values were $4 \mu \mathrm{g} / \mathrm{mL}$ for besifloxacin, $64 \mu \mathrm{g} / \mathrm{mL}$ for moxifloxacin, and $128 \mu \mathrm{g} / \mathrm{mL}$ for gatifloxacin. ${ }^{24}$

Abbreviations: $\mathrm{AUC}_{0-24 \mathrm{~h}}$, area-under-the-curve, or the total amount of drug delivered to conjunctival tissue in I day following I dose; mITT, modified intent-to-treat population $(\mathrm{N}=108)$.

a novel chloro-fluoroquinolone. It also provides the first report comparing the PK of these three fluoroquinolones in the conjunctiva of healthy volunteers. Because these three medications provide broad-spectrum coverage and cause few adverse reactions, they offer excellent therapeutic choices for treating bacterial conjunctivitis.

\section{Disclosures}

\section{References}

1. Tepedino ME, Heller WH, Usner DW, et al. Phase III efficacy and safety study of besifloxacin ophthalmic suspension $0.6 \%$ in the treatment of bacterial conjunctivitis. Curr Med Res Opin. 2009;25(5):1159-1169.

2. Karpecki P, Depaolis M, Hunter JA, et al. Besifloxacin ophthalmic suspension $0.6 \%$ in patients with bacterial conjunctivitis: A multicenter, prospective, randomized, double-masked, vehicle-controlled, 5-day efficacy and safety study. Clin Ther. 2009;31(3):514-526.

3. Hovding G. Acute bacterial conjunctivitis. Acta Ophthalmol. 2008;86(1):5-17.

4. Sheikh A, Hurwitz B. Antibiotics versus placebo for acute bacterial conjunctivitis. Cochrane Database Syst Rev. 2006;2(2):CD001211.

5. Grasbon T, Mino de Kaspar H, Klauss V. Coagulase-negative staphylococci in normal and chronically inflamed conjunctiva. Ophthalmologe. 1995;92(6):793-801.

6. Asbell PA, Colby KA, Deng S, et al. Ocular TRUST: nationwide antimicrobial susceptibility patterns in ocular isolates. Am J Ophthalmol. 2008;145(6):951-958.

7. United States Food and Drug Administration. Dermatologic and Ophthalmic Drugs Advisory Committee. Briefing Package for Besifloxacin hydrochloride ophthalmic suspension for the treatment of bacterial conjunctivitis. Bausch and Lomb, Inc. http://www.fda.gov/ohrms/dockets/ ac/08/briefing/2008-4397b1-00-Index.htm. Accessed July 10, 2009.

8. Cambau E, Matrat S, Pan XS, et al. Target specificity of the new fluoroquinolone besifloxacin in Streptococcus pneumoniae, Staphylococcus aureus and Escherichia coli. J Antimicrob Chemother. 2009;63(3):443-450. 
9. Wright DH, Brown GH, Peterson ML, Rotschafer JC. Application of fluoroquinolone pharmacodynamics. J Antimicrob Chemother. 2000;46(5):669-683.

10. Hyatt JM, McKinnon PS, Zimmer GS, Schentag JJ. The importance of pharmacokinetic/pharmacodynamic surrogate markers to outcome. Focus on antibacterial agents. Clin Pharmacokinet. 1995;28(2):143-160.

11. Forrest A, Nix DE, Ballow CH, Goss TF, Birmingham MC, Schentag JJ. Pharmacodynamics of intravenous ciprofloxacin in seriously ill patients. Antimicrob Agents Chemother. 1993;37(5):1073-1081.

12. Ambrose PG, Grasela DM, Grasela TH, Passarell J, Mayer HB, Pierce PF. Pharmacodynamics of fluoroquinolones against Streptococcus pneumoniae in patients with community-acquired respiratory tract infections. Antimicrob Agents Chemother. 2001;45(10):2793-2797.

13. Scaglione F, Mouton JW, Mattina R, Fraschini F. Pharmacodynamics of levofloxacin and ciprofloxacin in a murine pneumonia model: peak concentration/MIC versus area under the curve/MIC ratios. Antimicrob Agents Chemother. 2003;47(9):2749-2755.

14. Bedos JP, Azoulay-Dupuis E, Moine P, et al. Pharmacodynamic activities of ciprofloxacin and sparfloxacin in a murine pneumococcal pneumonia model: relevance for drug efficacy. J Pharmacol Exp Ther. 1998;286(1):29-35.

15. Wagner RS, Abelson MB, Shapiro A, Torkildsen G. Evaluation of moxifloxacin, ciprofloxacin, gatifloxacin, ofloxacin, and levofloxacin concentrations in human conjunctival tissue. Arch Ophthalmol. 2005;123(9):1282-1283.

16. Torkildsen G, O’Brien TP. Conjunctival tissue pharmacokinetic properties of topical azithromycin $1 \%$ and moxifloxacin $0.5 \%$ ophthalmic solutions: a single-dose, randomized, open-label, active-controlled trial in healthy adult volunteers. Clin Ther. 2008;30(11):2005-2014
17. Arnold DR, Granvil CP, Ward KW, Proksch JW. Quantitative determination of besifloxacin, a novel fluoroquinolone antimicrobial agent, in human tears by liquid chromatography-tandem mass spectrometry. JChromatogr B Analyt Technol Biomed Life Sci. 2008;867(1):105-110.

18. Aihara M, Miyanaga M, Minami K, et al. A comparison of fluoroquinolone penetration into human conjunctival tissue. J Ocul Pharmacol Ther. 2008;24(6):587-591.

19. Robertson SM, Curtis MA, Schlech BA, et al. Ocular pharmacokinetics of moxifloxacin after topical treatment of animals and humans. Surv Ophthalmol. 2005;50 Suppl 1:S32-S45.

20. Bowman LM, Si E, Pang J, Archibald R, Friedlaender M. Development of a topical polymeric mucoadhesive ocular delivery system for azithromycin. J Ocul Pharmacol Ther. 2009;25(2):133-139.

21. LaPlante KL, Rybak MJ, Tsuji B, Lodise TP, Kaatz GW. Fluoroquinolone resistance in Streptococcus pneumoniae: area under the concentrationtime curve/MIC ratio and resistance development with gatifloxacin, gemifloxacin, levofloxacin, and moxifloxacin. Antimicrob Agents Chemother. 2007;51(4):1315-1320.

22. Wilhelmus KR. Evaluation and prediction of fluoroquinolone pharmacodynamics in bacterial keratitis. $J$ Ocul Pharmacol Ther. 2003;19(5):493-499.

23. Proksch JW, Granvil CP, Siou-Mermet R, Comstock TL, Paterno MR, Ward KW. Ocular pharmacokinetics of besifloxacin following topical administration to rabbits, monkeys, and humans. J Ocul Pharmacol Ther. 2009;25(4):335-344.

24. Proksch JW, Chappa AK, Haas W, Morris TW. Besifloxacin, moxifloxacin, and gatifloxacin ocular tissue AUC/MIC ratios for fluoroquinolone-resistant organisms. Association for Research in Vision and Ophthalmology (ARVO). 2009. Abstract D905.
Clinical Ophthalmology

\section{Publish your work in this journal}

Clinical Ophthalmology is an international, peer-reviewed journal covering all subspecialties within ophthalmology. Key topics include: Optometry; Visual science; Pharmacology and drug therapy in eye diseases; Basic Sciences; Primary and Secondary eye care; Patient Safety and Quality of Care Improvements. This journal is indexed on

Submit your manuscript here: http://www.dovepress.com/clinical-ophthalmology-journal

\section{Dovepress}

PubMed Central and CAS, and is the official journal of The Society of Clinical Ophthalmology (SCO). The manuscript management system is completely online and includes a very quick and fair peer-review system, which is all easy to use. Visit http://www.dovepress.com/ testimonials.php to read real quotes from published authors. 